\title{
Neoliberalismo e integración "de hecho" en el Cono Sur: Argentina como exportadora de hidrocarburos
}

\author{
IGNACIO SABBATELLA $*$,**
}

Artículo recibido: 8 de agosto de 2017

Artículo aprobado: 24 de septiembre de 2017

Doi: http://dx.doi.org/10.12804/revistas.urosario.edu.co/desafios/a.5989

Para citar este artículo: Sabbatella, I. (2018). Neoliberalismo e integración "de hecho" en el Cono Sur: Argentina como exportadora de hidrocarburos. Desafíos, 30(1), 173-212. Doi: http://dx.doi.org/10.12804/revistas.urosario.edu.co/desafios/a.5989

\section{Resumen}

Entre 1989 y 2001 se configuró un proceso de integración energética en el Cono Sur de América, en el cual Argentina adoptó el papel de exportador de petróleo y gas natural, apesar de que históricamente había tenido que importar una parte de los hidrocarburos y sus derivados necesarios para cubrir la demanda interna. El objetivo de este articulo es analizar por qué y cómo se insertó Argentina como proveedor de bidrocarburos en este proceso. Como hipótesis se argumenta que fue menos una política de Estado que una consecuencia indirecta de la reforma neoliberal del sector de hidrocarburos, cuyos pilares fueron la desregulación del mercado, la privatización de la petrolera estatal Yacimientos Petroliferos Fiscales Sociedad del Estado (YPF) y la transformación simbólica y material del petróleo y gas en commodities. En términos de la CEPAL (1994), se trató más de una integración "de hecho" que de una integración impulsada

\footnotetext{
* Universidad de Buenos Aires, Facultad de Ciencias Sociales. Instituto de Investigaciones Gino Germani, Buenos Aires, Argentina.

** Consejo Nacional de Investigaciones Científicas y Técnicas (CONICET), Buenos Aires, Argentina. ORCID: http:// orcid.org/0000-0002-4535-0819 Correo electrónico: ignaciosabbatella@yahoo.com.ar
} 
porpolíticas. Tomando en cuenta estudios previos sobre la reforma del sector, se aplicó una estrategia metodológica basada en la investigación documental (Valles, 1997), a través de la recolección, sistematización y análisis de datos secundarios.

Palabras clave: integración "de hecho", hidrocarburos, neoliberalismo, commodities, Cono Sur.

\title{
Neoliberalism and De Facto Integration in the Southern Cone: Argentina as an Exporter of Hydrocarbons
}

\begin{abstract}
Between 1989 and 2001, a process of energy integration took place in the Southern Cone of Latin America, in which Argentina adopted the role of oil and natural gas exporter, although historically it had to import part of its consumption of bydrocarbons and derivatives in order to cover its domestic demand. The purpose of this article is to analyze why and how Argentina became a supplier of bydrocarbons. It is argued that this outcome was less a result of state policy than an indirect consequence of the neoliberal reform of the hydrocarbons sector, the pillars of which were market deregulation, the privatization of the state oil company Yacimientos Petroliferos Fiscales Sociedad del Estado (YPF), and the symbolic and material transformation of oil and gas in commodities. According to ECLAC, it was more a de facto rather than a policy-driven integration. Based on previous studies of the reform of the sector, a methodological strategy based on documentary research was applied through the collection, systematization and analysis of secondary data.
\end{abstract}

Keywords: De facto integration, bydrocarbons, neoliberalism, commodities, Southern Cone. 


\title{
Neoliberalismo e integração "de fato" no Cone Sul: a Argentina como exportadora de hidrocarbonetos
}

\begin{abstract}
Resumo
Entre 1989 e 2000 se configurou um processo de integração energética no Cone Sul da América, no qual a Argentina adotou o rol de exportador de petróleo e gás natural, apesar de que historicamente tivera que importar uma parte dos hidrocarbonetos e derivados necessários para cobrir a demanda interna. O objetivo deste artigo é analisar porquê e como se inseriu a Argentina como provedor de hidrocarbonetos neste processo. Como hipótese, argumenta-se que foi menos uma politica de Estado do que uma consequência indireta da reforma neoliberal do setor de hidrocarbonetos, cujos pilares foram a desregulação do mercado, a privatização da petroleira estatal Yacimientos Petroliferos Fiscales Sociedad del Estado (YPF) e a transformação simbólica e material do petróleo e gás em "commodities". Em termos da CEPAL (1994), tratou-se mais de uma integração "de fato" que de uma integração impulsada por politicas. Tomando em conta estudos prévios sobre a reforma do setor, aplicou-se uma estratégia metodológica baseada na investigação documental (Valles, 1997), através da recolecção, sistematização e análise de dados secundários.
\end{abstract}

Palavras-chave: integração "de fato", bidrocarbonetos, neoliberalismo, commodities, Cone Sul.

\section{Introducción}

Argentina cuenta con recursos hidrocarburíferos que le han permitido desarrollar una matriz energética con un fuerte sesgo fósil, pero nunca había podido generar excedentes por encima de su consumo interno, al menos hasta 1988. Hasta ese entonces importaba más productos energéticos de los que exportaba. Sin embargo, a mediados de la década del noventa se había convertido en el principal exportador de crudo y gas natural del Cono Sur de América ${ }^{1}$ a partir de un veloz desarrollo de la infraestructura transfronteriza y de la firma de acuerdos bilate-

\footnotetext{
1 Para facilitar el análisis en este trabajo denominaremos Cono Sur a la subregión del continente americano comprendida por Argentina, Chile, Uruguay, Paraguay y el sur de Brasil.
} 
rales y multilaterales. Al cabo de pocos años, la anhelada integración energética regional que permitiría conectar a los países productores con los países consumidores era un hecho. No obstante, de manera inédita Argentina se ubicó en el rol de proveedor de energía fósil. Las preguntas entonces son por qué y de qué manera se llevó a cabo este proceso.

El objetivo general de esta investigación es analizar el proceso de integración energética regional en el cual Argentina se insertó como exportador de hidrocarburos durante la década del noventa.

La integración energética se define como un "proceso de interconexión estratégica de las redes de energía en corredores internacionales, que permite, bajo un marco normativo común y servicios adecuados, su circulación ágil y eficiente" (Ruiz-Caro, 2010, p. 9). A su vez, la integración física, operativa y comercial en el ámbito energético de la región, permite "aprovechar más las sinergias, la infraestructura y los recursos disponibles y, de esta manera, beneficiar a mayores sectores de la población” (Ruiz-Caro, 2010, p. 9).

Durante la década del noventa, las iniciativas regionales se enmarcaron en la reestructuración neoliberal de las economías latinoamericanas en función de la liberalización comercial unilateral y multilateral, a diferencia de las estrategias de integración anteriores caracterizadas por el proteccionismo y la intervención estatal en pos del desarrollo industrial endógeno. En contraposición a este "viejo regionalismo" que se desenvolvió en la posguerra, el Banco Interamericano de Desarrollo (BID) denominó "nuevo regionalismo" a las iniciativas de la última década del siglo XX (BID, 2002).

A su vez, la Comisión Económica para América Latina y el Caribe (CEPAL) acuñó el término regionalismo abierto para caracterizar la estrategia de integración en curso, en los primeros años de la década del 90. La CEPAL identificaba dos caminos por los cuales estaba avanzando la integración regional. Por un lado, la integración impulsada por políticas, es decir, la integración formal que habitualmente se alcanza a través de acuerdos intergubernamentales y que se refuerza 
por la cercanía geográfica y la afinidad cultural de los países de la región. En la subregión, el acuerdo de integración más importante fue el Mercosur ${ }^{2}$. Por otro lado, la integración “de hecho", impulsada por las empresas en el marco de la transnacionalización de sus inversiones y de la producción y, al mismo tiempo, favorecida por la liberalización comercial unilateral.

En ese sentido, la CEPAL denominaba regionalismo abierto "al proceso que surge al conciliar ambos fenómenos: la interdependencia nacida de acuerdos especiales de carácter preferencial y aquella impulsada básicamente por las señales del mercado resultantes de la liberalización comercial en general" (CEPAL, 1994, p. 12).

Específicamente, el presente artículo se propone indagar si en dicho proceso de integración energética primó una integración "de hecho" o una integración impulsada por políticas. La hipótesis inicial de trabajo es que la integración regional de Argentina como exportador de hidrocarburos fue una consecuencia indirecta de la reforma del sector, a partir de los preceptos neoliberales: la apropiación material y simbólica de los hidrocarburos por parte de las petroleras privadas se orientó hacia la sobreexplotación de los yacimientos existentes que generó excedentes respecto a la demanda interna, que fueron volcados primordialmente a los mercados de los países limítrofes. Por tanto, el proceso de integración obedeció menos a una integración impulsada por políticas activas del Estado que a una integración "de hecho", a partir de la dirección implementada por las petroleras privadas para monetizar lo más rápidamente posible las reservas concesionadas. En ese sentido, denominaremos integración neoliberal a la primacía de la iniciativa privada o "de hecho" en el proceso de integración regional.

El presente artículo tiene como punto de partida estudios realizados sobre la reforma del sector de hidrocarburos en Argentina (Kozulj \& Bravo, 1993; Mansilla, 2007; Barrera, Sabbatella \& Serrani, 2012; Sabbatella, 2014; entre otros). El estado del arte sobre el proceso de integración

2 El Mercosur fue constituido al suscribirse el Tratado de Asunción por parte de Argentina, Brasil, Paraguay y Uruguay el 26 de marzo de 1991. 
energética de Argentina con la región es acotado y está focalizado en distintos aspectos de la integración gasífera y menos en el rol exportador que asumió el país tanto en gas como en petróleo. Solamente Kozulj (2008) vincula en forma directa la integración gasífera con la iniciativa privada en el contexto de la reforma, pero tratándose de un informe sectorial no profundiza una perspectiva teórica que contribuya a entender el proceso en su dimensión histórico-político-económica. La Fundación Bariloche (2007) y Bertero (2007) se enfocaron en la debilidad del marco regulatorio e institucional sobre el cual se llevó adelante la interconexión gasífera. Navajas (2008), en cambio, se centró en la ausencia de previsión de contingencias políticas y económicas en los contratos de comercialización de gas entre privados a partir del caso argentino-chileno. Por último, mencionamos el trabajo de Gamboa y Huneeus (2007) sobre el proceso de integración gasífera desde la perspectiva chilena que muestra los límites del mismo, dado el protagonismo de la iniciativa privada y el rol subsidiario del Estado. Teniendo en cuenta estas contribuciones, el artículo pretende comprender con mayor profundidad teórica la transformación de Argentina en proveedor de hidrocarburos dentro de la subregión luego de la reforma del sector bajo el paradigma neoliberal.

En cuanto a la metodología, se aplicó la estrategia de la investigación documental (Valles, 1997, p. 99). El trabajo de investigación se orientó a la recolección, sistematización y análisis de fuentes documentales y estadísticas, con el fin de abordar un proceso histórico de carácter económico-político. En este artículo se utilizaron dos tipos de documentos. Por un lado, documentos numéricos (estadísticos) del Ministerio de Energía y Minería de la Nación (MINEM), del Instituto Argentino del Petróleo y Gas (IAPG) y del Ente Nacional Regulador del Gas (ENARGAS) con el fin de analizar la dinámica sectorial a partir de la elaboración de los datos de extracción y de comercio exterior de hidrocarburos. Por otro lado, documentos no numéricos o literarios: los acuerdos internacionales bilaterales y multilaterales firmados por Argentina en materia de hidrocarburos (anexo 1), atendiendo especialmente al rol del Estado y su relación con el sector privado, y todos los números mensuales del periodo de estudio de la Revista Petrotecnia, editada por el IAPG, en la cual se suelen verter las opiniones de los principales representantes de la industria petrolera y gasífera del país. 
En esos números, se rastrearon las apelaciones respecto a la estrategia exportadora de hidrocarburos y al proceso de integración regional. Una vez obtenido el registro, se realizó un análisis de contenido cualitativo ${ }^{3}$.

En el siguiente apartado se explicitará el marco teórico de la investigación y se realizará una breve descripción del funcionamiento del sector previo a la reforma, además de un recorrido por los principales antecedentes de integración energética en la región. En el tercer apartado se contextualizará la reforma neoliberal del sector y se expondrán sus características centrales. Por último, se analizará la integración bajo su forma neoliberal: la creación material y simbólica del mercado subregional y la generación de saldos exportables destinados a los mercados limítrofes.

\section{Marco teórico y antecedentes históricos}

\section{Marco teórico}

El marco teórico de investigación se nutre de diversas corrientes teóricas con el fin de abordar la compleja relación sociedad-naturaleza, en abstracto, y la relación capitalismo-naturaleza, en particular: el marxismo ecológico, la ecología política, la teoría gramsciana, la teoría de la regulación francesa y los trabajos de la economía heterodoxa argentina (sobre todo, el Área de Economía y Tecnología de Flacso Argentina) para entender los ciclos económico-políticos a escala nacional.

Desde nuestra perspectiva, existe una correspondencia no automática entre el establecimiento de un bloque hegemónico, que remite a un régimen de acumulación y una forma de Estado particular, con la difusión de una ideología o representación hegemónica sobre la apropiación social de la naturaleza. Esta relación no siempre se presenta

\footnotetext{
3 Es una técnica de interpretación de textos, ya sean escritos, grabados, pintados o filmados, entre otros, que se basa en la lectura (textual o visual) como instrumento para recoger la información, que a diferencia de la lectura común debe realizarse siguiendo el método científico, es decir, debe ser sistemática, objetiva, replicable y válida (Andreu Abela, 2001, p. 2).
} 
de manera transparente y monolítica, sino que frecuentemente se encuentra en tensión con otras valoraciones pertenecientes a sectores que disputan la hegemonía político-económica. A continuación, se definirán estas categorías con mayor precisión.

Independientemente de las condiciones históricas, el acto de apropiación de la naturaleza que inicia el metabolismo social contiene dos dimensiones recíprocamente condicionadas: una apropiación material, tangible o "dura", en la cual los hombres se apropian y transforman ecosistemas para satisfacer sus necesidades y deseos, y otra apropiación simbólica, intangible o "suave", en la cual se articulan con el mundo natural por medio de las creencias, el conocimiento, la percepción, la estética, la imaginación y/o la intuición (Toledo, 2008). Precisamente, la ecología política no solo estudia la dimensión material de la apropiación de la naturaleza, sino también su dimensión simbólica y conflictiva (Martínez Alier, 2004; Palacio, 2006).

En el contexto de la expansión capitalista a nivel global, el marxismo ecológico plantea que existe una tendencia creciente hacia la apropiación privada y mercantilización de la naturaleza (O'Connor, 2001; Sabbatella \& Tagliavini, 2011). Sin embargo, siguiendo los aportes de la ecología política, a nivel local pueden coexistir conflictivamente distintas formas ideológicas y simbólicas sobre el uso de los bienes y servicios que provee el mundo natural, donde una de ellas se vuelve hegemónica o dominante de acuerdo con la correlación de fuerzas vigente. Esto se debe a la existencia de distintas fracciones de capital con intereses contrapuestos y a la movilización de los sectores populares, que también disputan las modalidades de apropiación (Sabbatella, 2014).

En términos gramscianos, la hegemonía de un sector o clase social supone el dominio económico, político y social a través del poder del Estado, al mismo tiempo que la dirección ideológica y cultural del resto de la sociedad (Gramsci, 1986; 2001). Ella toma cuerpo en un determinado régimen de acumulación a escala nacional y en una forma de Estado determinada, siguiendo los aportes de la teoría de la regulación francesa. 
La categoría régimen o patrón de acumulación de capital designa el "conjunto de regularidades que aseguran una progresión general y relativamente coherente de la acumulación del capital" (Boyer, 2016, p. 80). Las formas del Estado son compromisos institucionalizados que crean reglas y regularidades en los gastos e ingresos públicos (Boyer, 2016, p. 63). La intervención del Estado y la relación entre esfera pública y privada configuran, a su vez, una forma de adhesión al régimen internacional, es decir, las modalidades de inserción del Estado-nación en la economía internacional.

Entendemos que, de acuerdo con el régimen de acumulación y las relaciones de fuerza vigentes — sumado a otros factores institucionales, tecnológicos, económicos y sociales_- la forma de Estado puede variar, con distintos matices, entre un rol administrador/productor/ empresario de los bienes naturales y servicios ambientales o, por el contrario, adoptar su expresión mínima para liberar su regulación a las fuerzas del mercado.

En otro artículo nos hemos enfocado en el vínculo orgánico entre la hegemonía neoliberal, el régimen de acumulación de valorización financiera, la forma de Estado neoliberal y el proceso de apropiación material y simbólico de los hidrocarburos como commodities en Argentina durante la década del noventa (Sabbatella, 2014). Aquí volveremos sobre ese vínculo para comprender la modalidad de inserción de Argentina como país exportador de petróleo y gas a nivel subregional.

En la medida en que esa inserción ha sido moldeada por la primacía de la iniciativa privada o "de hecho", en los términos de la CEPAL (1994), se denominará integración neoliberal para dar cuenta del esquema privatizador y desregulador implementado desde el propio Estado en función de un nuevo proyecto hegemónico.

\section{Industrialización por sustitución de importaciones, autoabastecimiento y YPF}

Hasta fines de la década del ochenta gran parte de la explotación de hidrocarburos había permanecido bajo el control estatal a través de la 
empresa Yacimientos Petrolíferos Fiscales Sociedad del Estado (YPF) pese a cierta apertura hacia la participación del capital privado en algunos pasajes de la historia petrolera argentina. Bajo el predominio social de la ideología del nacionalismo petrolero ${ }^{4}$, el gas y el petróleo sobre todo eran considerados recursos estratégicos. Su apropiación material y simbólica estaba dirigida fundamentalmente a abastecer el desarrollo del régimen de industrialización por sustitución de importaciones (ISI) ${ }^{5}$, el cual a su vez configuraba una forma de Estado benefactor/empresario.

La articulación entre la ISI, el Estado benefactor y la asignación estratégica de los hidrocarburos tuvo su auge, aunque con distintas oscilaciones $^{6}$, entre 1946, cuando comenzó la primera presidencia de Juan Domingo Perón, y 1976, cuando el golpe de Estado cívicomilitar interrumpió abruptamente la ISI y desarticuló su base social por medio del terrorismo de Estado.

Durante la última dictadura cívico-militar (autodenominada Proceso de Reorganización Nacional) entre los años 1976-1983, tomó forma la "privatización periférica” de YPF, mediante el endeudamiento de la empresa con el objetivo de entregar divisas al mercado financiero doméstico y la transferencia de áreas en producción a operadores privados para que las explotaran como contratistas (Basualdo \& Barrera, 2015). Los contratistas tenían la obligación de vender el petróleo extraído de estos yacimientos a la petrolera estatal. Existía un sistema de administración

\footnotetext{
4 El nacionalismo petrolero atravesaba sectores políticos, intelectuales, sindicales y militares y tenía como pilares la "industrialización, la autosuficiencia económica, la hostilidad al capital extranjero y fundamentalmente la necesidad de dar al Estado un papel activo como promotor de la empresa pública" (Favaro \& Morinelli, 1991, p. 69).

5 Los rasgos comunes de la ISI, al menos en los países de mayores dimensiones de la región, fueron un fuerte peso del Estado como orientador del proceso y agente productivo; un control público de los flujos financieros orientado a apoyar el proceso de industrialización, y una estrecha articulación entre la expansión de la capacidad productiva y el consumo interno (Basualdo \& Arceo, 2006).

6 El precontrato con la California Argentina de Petróleo S.A. firmado por Perón; los contratos de Frondizi con empresas privadas hasta 40 años de plazo, que actuaban por cuenta y para YPF; la anulación de los mismos durante la presidencia de Illia, y la Ley 17319 de Hidrocarburos, aún vigente, sancionada por la dictadura de Onganía, que introdujo la participación privada en toda la cadena.
} 
centralizada por el cual YPF compraba todo el crudo y luego se asignaban cupos para cada refinería a través de la "mesa de crudos" que funcionaba en el ámbito de la Secretaría de Energía (Kozulj, 2002).

No fue hasta finales del gobierno de Alfonsín que se intentaría reformar este sistema centralizado. El Plan Olivos II o Petroplan, presentado en 1988, proponía abrir la participación privada en áreas marginales y centrales que la YPF tenía en producción. Para hacerlo más atractivo al capital petrolero, el plan garantizaba la libre disponibilidad del crudo obtenido y postulaba como objetivo final la eliminación de la Mesa de Crudos y la libre adquisición del petróleo requerido en el mercado (Kozulj \& Bravo, 1993). Finalmente, el Petroplan no prosperó dada la debilidad política del alfonsinismo y de la fuerte oposición por parte del peronismo y de sectores sindicales a pesar de haber sido el intento más importante por deshacer el andamiaje estatal que sostenía a los hidrocarburos como "recursos estratégicos". Desde nuestra perspectiva, constituyó un antecedente significativo del proceso de comoditización que se llevaría a cabo al año siguiente a través del otorgamiento de la libre disponibilidad de los recursos extraídos y de la desregulación del sector.

\section{Ensayos previos de integración}

Como afirma Hallack (2014), en Sudamérica la construcción de infraestructura de interconexión entre los distintos países estuvo históricamente fundada en compromisos bilaterales.

En ese sentido, el primer antecedente de integración energética responde a la firma de acuerdos para la construcción de tres proyectos hidroeléctricos binacionales: el Acta sobre el Río Uruguay en 1938 entre Argentina y Uruguay que daría lugar a la represa de Salto Grande; el Tratado de Yacyretá entre Argentina y Paraguay (1973), y la creación de la Entidad Binacional Itaipu entre Brasil y Paraguay (1974). Paralelamente a la creación de las represas binacionales se intensificó el proceso de interconexión eléctrica entre los países, aunque ya existían antecedentes entre Brasil y Uruguay en la década del sesenta. 
Los proyectos multilaterales de integración regional en materia energética previos a la década del noventa fueron ambiciosos, aunque con pocos resultados tangibles. El primero de ellos tuvo lugar en 1965 con la creación de la organización de Asistencia Recíproca Petrolera Estatal Latinoamericana (ARPEL), a través de la cual los países productores de petróleo intentaron coordinar la comercialización del petróleo y de sus productos derivados. Sin embargo, distintos factores desdibujaron su propósito: la inestabilidad de sus funcionarios — dependientes del gobierno de turno-, la excesiva burocratización y superposición de funciones tanto a nivel interno como con otras instituciones regionales, la ampliación de la membrecía que comenzó en la década de 1980 y, finalmente, su vaciamiento en las postrimerías del siglo xx bajo el influjo neoliberal (Yazbek, 2012).

En 1972, los ministros de energía de la región dieron lugar a la creación de la Organización Latinoamericana de Energía (OLADE), cuyo propósito es desarrollar la cooperación técnica y jurídica, así como la coordinación de las políticas energéticas de los países miembros. No obstante, su papel en el mercado energético regional hasta la actualidad ha sido limitado (Cerra \& Yazbek, 2013).

En cuanto a la integración física bilateral en materia hidrocarburífera, el único antecedente en toda la región era el gasoducto boliviano-argentino. Bolivia comenzó a exportar gas a Argentina en 1972 cuando los Yacimientos Petrolíferos Fiscales Bolivianos (YPFB) y Gas del Estado dieron inicio al contrato de compra-venta a través del primer gasoducto transfronterizo construido en Suramérica, el Yabog, que unía Santa Cruz de la Sierra y Campo Duran, provincia de Salta. Aunque tenía una vigencia de veinte años, el contrato se extendió mediante sucesivas prórrogas hasta 1999. El principal propósito del contrato era fortalecer acuerdos de carácter geopolítico entre los gobiernos militares de ambos países, al mismo tiempo que permitía a Bolivia una vía para explotar uno de sus recursos más abundantes para incentivar el desarrollo económico nacional. Es decir que en aquella primera etapa que se extendió entre 1972 y 1999, la importación de gas boliviano 
no tuvo como principal objetivo fortalecer el suministro interno en Argentina (Kozulj, 2008) ${ }^{7}$.

\section{La reforma neoliberal}

\section{El contexto regional}

Siguiendo a David Harvey (2007), la crisis de sobreacumulación de capital a nivel global en la década del setenta otorgó el marco propicio para la difusión de la hegemonía neoliberal a nivel internacional, bajo el liderazgo de EE.UU. al igual que en la etapa posterior a la Segunda Guerra Mundial, pero con un mayor peso del capital financiero. En esa línea, el neoliberalismo se entiende como un proyecto político tendiente a restablecer las condiciones para la acumulación del capital y restaurar el poder de las elites económicas (p. 24) ${ }^{8}$.

En América Latina, el neoliberalismo se proyectó a través del Consenso de Washington, con el auspicio del Fondo Monetario Internacional (FMI) y del Banco Mundial, cuyos principios podrían sintetizarse en una rígida disciplina presupuestaria, una economía de mercado y la apertura al comercio internacional. La región se vio pronto sometida al paquete de ajuste estructural, desregulación y privatización, que permitía que afloraran nuevas oportunidades de negocios para el capital sobreacumulado en los países industrializados. Se llevó a cabo un profundo proceso de reconversión de la estructura productiva que desguazó la incipiente industria de sustitución en función del capital financiero, la producción primaria y los servicios.

\footnotetext{
A partir de 2004, Argentina volvió a importar gas boliviano con el fin de complementar la oferta interna, debido a la declinación de la producción local y el incremento de la demanda.

8 "El neoliberalismo es, ante todo, una teoría de prácticas político-económicas que afirma que la mejor manera de promover el bienestar del ser humano consiste en no restringir el libre desarrollo de las capacidades y de las libertades empresariales del individuo [...] El papel del Estado es crear y preservar el marco institucional apropiado para el desarrollo de estas prácticas" (Harvey, 2007, p. 8).
} 
Durante la década de los noventa, buena parte de los países productores de América Latina y el Caribe, con la excepción de México, llevaron adelante reformas en el sector upstream (exploración y extracción de hidrocarburos) con el fin de incorporar inversión privada, aunque con distintos grados de apertura. A partir del trabajo de Campodónico (2004), realizaremos a continuación un breve repaso de los casos más sobresalientes.

En Brasil, la apertura petrolera comenzó en 1995 con la Enmienda Constitucional 5, la cual permitió el ingreso de capitales privados al sector. Posteriormente, la Ley de Petróleo 9478 de 1997 abrió la participación del capital privado a la exploración y explotación de campos petroleros, que terminó con el monopolio de Petrobras. Asimismo, se estableció la apertura del capital social de la empresa, diferenciando entre acciones ordinarias — que confieren derecho a voto y en las que el Estado debe mantener la mayoría para fijar la política de la empresa- y acciones preferenciales — que no otorgan derecho a voto y que permiten al sector privado tener mayoría-. Mediante la creación de la Asociación Nacional de Petróleo (ANP) —ente regulador de la industria petrolera, dependiente del Ministerio de Energía de Brasil— se realizaron rondas de licitación de áreas de exploración en las cuales Petrobras compitió en asociación con empresas extranjeras.

En los países importadores del Cono Sur, cabe destacar que tanto Chile como Uruguay mantuvieron la propiedad estatal de sus empresas petroleras: Empresa Nacional de Petróleo (ENAP) y Administración Nacional de Combustibles, Alcohol y Portland (ANCAP), respectivamente.

Saliendo de la subregión, la apertura al capital privado en Venezuela se plasmó en el Plan Corporativo de Largo Plazo, adoptado por la estatal Petróleos de Venezuela (PDVSA) en 1991, que se realizó por medio de tres modalidades: a) contratos de servicios para la recuperación secundaria en campos marginales; b) asociaciones estratégicas para la explotación de crudo pesado en la Faja del Orinoco, y c) contratos de exploración de nuevas reservas de petróleo bajo el esquema de ganancias compartidas. 
En Colombia, se introdujeron modificaciones a los contratos de asociación con la Empresa Colombiana de Petróleos (Ecopetrol) con el objetivo de atraer un mayor flujo de inversión extranjera al sector.

En Ecuador, se introdujo la modalidad de contratos de participación en la producción en 1993, en los cuales los contratistas tenían derecho a disponer libremente de los hidrocarburos que les correspondían, una vez entregada la participación de la producción perteneciente al Estado. En 1999, se dispuso la creación de contratos de administración compartida (managment sharing) y joint ventures entre empresas extranjeras y Petroecuador en las áreas petroleras más grandes.

En tanto que la profunda reforma del sector en Argentina solo es comparable a los casos de Bolivia y Perú, donde se privatizaron las respectivas empresas estatales. Bolivia llevó a cabo una estrategia de privatización a través de la capitalización de YPFB, que implicó su división en dos sociedades anónimas mixtas (SAM), Andina y Chaco. El 50\% de las acciones de ambas sociedades fue adquirido por distintos consorcios internacionales a cambio de sendos compromisos de inversión, mientras que la mitad restante quedó en manos de los fondos de pensiones bolivianos. A su vez, los contratos de asociación y de operación existentes se convirtieron a la nueva modalidad de riesgo compartido a cambio de compromisos mínimos de inversión para los años siguientes. Los contratistas adquirían el derecho a explorar, explotar y comercializar los hidrocarburos extraídos, excepto el volumen requerido para satisfacer el consumo interno de gas natural y para cumplir los contratos de exportación de YPFB.

Por último, en el caso peruano la venta de activos menores de Petroperú se inició en 1992 y a partir de 1996-1997 se optó por una "privatización fragmentada" de los activos más importantes (lotes productores y su refinería más grande): la empresa fue dividida en unidades de negocio, que luego se vendieron individualmente a empresas extranjeras. Como propiedad de Petroperú quedaron únicamente una refinería, un oleoducto y terminales y plantas de abastecimiento de combustibles en el interior del país. 
Con todo, el caso argentino presenta ciertas particularidades respecto al desarrollo del sector en Bolivia y Perú. Mientras que Argentina pasó de ser un país que importaba buena parte de sus necesidades energéticas a ser un exportador neto de petróleo y gas en un periodo de tiempo muy corto, Bolivia ya era un país exportador de gas en el marco de un mercado interno pequeño con relación a su dotación de recursos fósiles. Perú, en cambio, se convirtió en exportador de gas natural licuado (GNL) a países extraregionales una década más tarde, a partir del descubrimiento de nuevas reservas de gas y de la disponibilidad de esa tecnología.

Sobre estas reformas locales se lanzó un proyecto energético continental. En el marco del Área de Libre Comercio de las Américas (ALCA), EE.UU. promovió la Integración Energética Hemisférica (IEH), cuyos lineamientos básicos eran la liberalización del mercado energético regional y la implementación de marcos favorables a la inversión privada asentándose en los procesos de privatización, desregulación y apertura que con distintos grados ya estaban en marcha en buena parte de los países del continente. La iniciativa fue lanzada en la primera Cumbre Hemisférica de las Américas en Miami en diciembre de 1994, pero el documento no abordó de manera abierta la relación entre la privatización del sector y la cooperación energética, ya que hasta ese momento los dos principales productores de petróleo, Venezuela y México, y el principal importador latinoamericano de energía, Brasil, mantenían la protección de sus empresas estatales. Fue por ello que la integración energética quedó enmarcada en la cooperación y el fomento de políticas de eficiencia (Arriaga Rodríguez, 2002). Los Jefes de Estado adoptaron un plan de acción que dio lugar a cinco reuniones de ministros de energía entre 1995 y 2001 en las cuales se buscó potenciar las acciones iniciadas por los países en forma aislada, impulsando la participación privada en la integración energética. Con todo, la IEH no tuvo mayor incidencia, aunque las reformas de mercado continuaron avanzando en algunos países al igual que los acuerdos bilaterales. 


\section{Privatización, desregulación y comoditización}

En Argentina, la dictadura cívico-militar puso fin al proceso de industrialización por sustitución de importaciones iniciado en la década de 1930 con la firme convicción de implantar un modelo financiero y de ajuste estructural (Azpiazu \& Schorr, 2010). La hegemonía del capital financiero a nivel mundial y la apertura instrumentada a partir de 1976 configuraron un nuevo patrón de acumulación basado en la valorización financiera ${ }^{9}$ a escala nacional.

Sin embargo, no fue hasta el triunfo de Carlos Menem, en las elecciones presidenciales de 1989, que se asentaron las bases para la hegemonía neoliberal y la constitución de un nuevo bloque de poder. El extenso programa de privatizaciones que condujo el gobierno de Menem trajo consigo el apoyo de la comunidad de negocios, confluyendo los intereses de los acreedores externos y sus representantes institucionales — fundamentalmente el Banco Mundial y el FMI- y de los grandes grupos económicos locales nacionales y extranjeros (Azpiazu \& Basualdo, 2004). En términos de Harvey (2007), el aparato estatal adoptó la forma de Estado neoliberal, cuya misión fundamental era facilitar las condiciones para una provechosa acumulación de capital tanto por parte del capital extranjero como del doméstico. En ese marco se inscribe la reforma estructural del sector de hidrocarburos.

Bajo los preceptos neoliberales, la reforma del sector se erigió sobre tres pilares: a) desregulación del mercado; b) fragmentación y privatización de YPF, y c) transformación de los hidrocarburos en commodities. Mediante un paquete de leyes y decretos el menemismo transformó velozmente la fisonomía y funcionamiento de la actividad petrolera en apenas seis meses. La Ley 23696 de Reforma del Estado fue el

\footnotetext{
9 La valorización financiera se define como "un proceso en el cual las fracciones del capital dominante contrajeron deuda externa para luego realizar con esos recursos colocaciones en activos financieros en el mercado interno (títulos, bonos, depósitos, etc.) para valorizarlos a partir de la existencia de un diferencial positivo entre la tasa de interés interna e internacional y posteriormente fugarlos al exterior" (Basualdo, 2006, p. 130).
} 
cimiento sobre el cual se edificó el esquema privatizador. Declaró el estado de emergencia a la prestación de los servicios públicos, a la ejecución de los contratos públicos y a la situación económica y financiera del Estado nacional, incluyendo las empresas públicas. Estableció las facultades del Ejecutivo para proceder a las privatizaciones, contrataciones y concesiones de ciertas empresas o sectores sin la necesidad de sancionar una ley especial por parte del Congreso. Es decir, que posibilitaba la desmonopolización o desregulación de los servicios. En el caso de YPF contemplaba concesiones o asociaciones en áreas de exploración y explotación y la constitución de sociedades mixtas en las denominadas áreas centrales.

En el mismo semestre se dictaron tres decretos que desregularon el mercado de hidrocarburos: 1055/89, 1212/89, 1589/89. Los mismos establecieron las siguientes medidas y principios:

- Reconversión de los contratos con operadores privados en concesiones de explotación

- Eliminación de la Mesa de Crudos y la libre disponibilidad de la totalidad de los hidrocarburos obtenidos

- Libre importación de petróleo y derivados sin autorización ni aranceles

- Libre exportación de petróleo, mientras que la exportación de gas se podía tramitar pidiendo un permiso a la Secretaría de Energía

- Libre disponibilidad de divisas hasta el $70 \%$

- Libertad de precios del petróleo y derivados

- Libre instalación de refinerías y bocas de expendio

$\mathrm{Al}$ mismo tiempo, los decretos desreguladores pusieron en marcha la fragmentación de YPF, es decir, la escisión de activos de la empresa y su posterior venta o concesión. Posteriormente, el Decreto 2778 de 1990 estableció el Plan de Transformación Global de la petrolera estatal y delimitó el cronograma para desprenderse de sus principales activos. La empresa fue convertida en sociedad anónima de capital abierto, con lo que a partir de ese momento comenzó a regirse por el derecho privado, aunque continuaría siendo una empresa estatal en la medida que el Estado mantendría la mayoría de las acciones de su capital. 
En 1992, el gobierno de Menem logró reunir el apoyo de las petroleras privadas tanto nacionales como internacionales, la dirigencia sindical, los gobernadores de las provincias petroleras, los organismos financieros internacionales y los medios de comunicación para avanzar en la privatización de YPF S.A. A través de la sanción de la Ley 24145 de "Federalización de los hidrocarburos y privatización de YPF" se habilitó la venta de las acciones de la empresa, aunque el Estado nacional debía conservar como mínimo el 20\% del capital accionario hasta la sanción de una nueva ley ${ }^{10}$. En 1995, la Ley 24474 autorizó al Poder Ejecutivo Nacional reducir su tenencia del paquete accionario hasta una sola acción, la "acción de oro", que permitió que en 1999 la empresa española Repsol adquiriera casi la totalidad de las acciones.

La desregulación y privatización del mercado de hidrocarburos tuvo como trasfondo la comoditización de los hidrocarburos, es decir, el pasaje de la concepción del petróleo y gas como recursos estratégicos hacia su consideración como simples mercancías exportables o commodities: productos indiferenciados destinados a la exportación cuyos precios se fijan internacionalmente. En términos marxistas, el objetivo era divorciar el valor de uso de los hidrocarburos como bienes energéticos para el abastecimiento interno de su valor de cambio en el mercado externo. Esa operación fue realizada desde el Estado bajo su forma neoliberal por dos vías complementarias: normativamente, por medio de la libre disponibilidad y libre exportación del recurso extraído, y simbólicamente, por medio de un discurso agresivo por parte de las autoridades gubernamentales hacia la política petrolera que había caracterizado a Argentina desde la creación de YPF — aun con los matices señalados - con la finalidad de despejar el camino hacia la apropiación privada de los hidrocarburos y a la sobreexplotación de los yacimientos descubiertos por la petrolera estatal.

Cabe aclarar que, a diferencia del petróleo, existían límites normativos y límites técnicos para la exportación del gas natural. Por un lado, en

\footnotetext{
10 En otro trabajo se analizó el desempeño de YPF con el 20\% de participación accionaria estatal durante el periodo 1993-1998, en el que se concluyó que la empresa se manejó con criterios privados pese a que el Estado era el mayor accionista.
} 
el artículo 3 de la Ley 24076 de privatización de Gas del Estado se introdujo una condición: "las exportaciones de gas natural deberán, en cada caso, ser autorizadas por el Poder Ejecutivo Nacional, dentro del plazo de noventa días de recibida la solicitud, en la medida que no se afecte el abastecimiento interno". Más adelante, se verá que el resguardo del mercado interno se replicaría en los acuerdos bilaterales que el Gobierno argentino firmó con los Gobiernos de los países limítrofes.

Por otra parte, la comercialización del gas tiene ciertos límites técnicos para ser considerado como un commodity. Mientras que el petróleo, dada la facilidad de su transporte, se comercializa globalmente y está regido por un precio internacional, para el gas no existe un mercado mundial sino varios mercados regionales, tales como los de Europa occidental, Estados Unidos y extremo oriente. El precio del gas natural, sujeto a la ubicación de los yacimientos y su transporte, tiene importantes variaciones e influencias regionales. Aunque desde la óptica neoliberal el desarrollo de la tecnología del GNL a gran escala generaría las condiciones para su comoditización, lo que permitiría crear un mercado mundial y, por lo tanto, un precio de referencia dada la facilidad para transportarlo vía marítima.

\section{Integración neoliberal}

\section{La creación del mercado regional}

La concesión de áreas ya exploradas y/o explotadas por la gestión estatal de YPF y un marco regulatorio más que ventajoso, permitían al capital petrolero proyectar un rápido crecimiento de la producción por encima de las necesidades del mercado interno. En ese sentido, es posible rastrear la construcción discursiva del sector privado, a través de sus principales referentes, que ubicó a Argentina como un país excedentario y al resto de los países de la subregión como destinatarios de esos excedentes. El presidente de la petrolera Bridas, Alejandro Bulgheroni, trazaba a Argentina principalmente y a Bolivia como exportadores de hidrocarburos en el Cono Sur, teniendo en cuenta que el resto de los países de la subregión eran deficitarios 
(Petrotecnia, 1994, p. 22). Michael Tucker, Gerente General de Transportadora de Gas del Sur SA, afirmaba que: "no cabe duda que, de los países que integran el Cono Sur, Argentina es lejos el más rico en reservas explotables de hidrocarburos. Por ende, Argentina debería ser uno de los principales proveedores de energía de la región" (Petrotecnia, 1994, p. 32).

No obstante, el mercado del Cono Sur debía ser creado material y simbólicamente. En el registro discursivo realizado aparece en reiteradas oportunidades el mercado subregional como condición del crecimiento sectorial. Carlos de Jesús, presidente de la Cámara de la Industria del Petróleo y de Esso SAPA, destacaba que "la ampliación de los mercados, ya sea por el Mercosur u otra clase de integración, representa mayores posibilidades de crecimiento para el sector petrolero" (Petrotecnia, 1994, p. 20). Asimismo, Patrick Rambaud, gerente general de Total Austral S.A., opinaba que "el desarrollo del mercado del Cono Sur es un proceso fundamental para el crecimiento del sector energético, particularmente para el mercado del gas" (Petrotecnia, 1994, p. 31). José Manuel Elicabe — presidente de Isaura - enfatizaba el rol importador de los mercados de Chile y Brasil que aparecían como "los más importantes para ubicar nuestros excedentes de petróleo crudo [...] Estos mismos mercados deberían contribuir de manera más acentuada al desarrollo gasífero..." (Petrotecnia, 1994, p. 30). Por último, Oscar Mussini, gerente de la División Gas Natural de YPF S.A, aseguraba que "las grandes posibilidades de crecimiento de la demanda de gas natural de Argentina se concentran en el largo plazo fundamentalmente en los proyectos de exportación" (Petrotecnia, 1996, p. 24).

Los intereses y expectativas de los actores privados sobre el proceso de integración regional giraban en torno a la valorización de las reservas locales de hidrocarburos. Paradójicamente, presentaban a la estrategia exportadora como garante de la actividad exploratoria: una mayor demanda traería consigo la búsqueda de nuevas reservas. El CEO de Pérez Companc, Oscar Vicente, consideraba que no debían ponerse obstáculos a los proyectos de exportación dado que "alientan nuevas exploraciones [y] posibilitan la comercialización de descubrimientos 
ya realizados" (Petrotecnia, 1997, p. 12). También, Roberto Monti, presidente de YPF S.A., aseveraba que el "reaseguro para este mercado es que se exporte" ya que era el incentivo para seguir explorando y que el gas sería insuficiente aun cuando se restringiera la exportación (Petrotecnia, 1997, p. 13). Sin embargo, la estrategia exportadora como señal inversora no se verificó en los hechos: la cantidad de pozos exploratorios cayó 81 \% entre el máximo de 164 pozos en 1995 y el mínimo de 30 en 1999, según datos del IAPG. El corolario de esta estrategia fue una significativa caída del horizonte de reservas, indicador que mide en años la relación entre reservas comprobadas y extracción en un determinado año. Según datos del MINEM, entre 1988 y 2001 el horizonte de reservas de petróleo cayó de 13,9 a 10,4 años; mientras que en el caso del gas se trató de una merma aún más pronunciada ya que el horizonte de reservas se redujo de 34 a 15,9 años.

Una vez iniciada la reforma del sector, los operadores privados del mercado argentino formaron consorcios internacionales con empresas extranjeras - tanto privadas como estatales - para materializar la infraestructura de exportación.

El primer ducto transfronterizo fue el emplazado en 1994 con dirección a Chile para exportar crudo neuquino. Se trata del Oleoducto Trasandino, el cual tiene una capacidad máxima de transporte de 115 mil barriles por día (b/d) y une Puesto Hernández, en la Cuenca Neuquina, con Concepción (Chile), cruzando la Cordillera de Los Andes. Su construcción corrió por cuenta de un consorcio privado conformado por YPF S.A. con una participación del 57,5\%, Banco Río con el 30\% y la chilena ENAP con el 12,5\%. En aquel entonces, Chile importaba el 75\% de sus necesidades de petróleo desde Nigeria y Medio Oriente. Por medio del oleoducto, reemplazaría la mitad de esas importaciones por un crudo a más bajo costo al evitar el flete por barco desde aquellos países. El crudo tenía como destino principal la refinería Petrox, propiedad de ENAP, mientras que los excedentes de producción no vendidos en el mercado chileno podrían cargarse en buques tanques para ser comercializados a través del Pacífico ( $E l$ Cronista, 1994). Para el Presidente de YPF S.A., José Estenssoro: 
todos los países fronterizos de la Argentina ofrecen inmejorables oportunidades de negocios para el conjunto de la industria del petróleo y el gas natural en la Argentina [y, precisamente, la inauguración del Oleoducto Trasandino era] un gran ejemplo [ya que] no solo confirmó la posibilidad real de integración económica que pueden motorizar empresas que operan en condiciones de mercado (el oleoducto se financió totalmente sin avales estatales) sino que abrió una perspectiva nueva, que habrá de transcender también los mercados regionales (Petrotecnia, 1994, p. 21).

Si la exportación de crudo a los mercados limítrofes se complementaba vía terrestre o marítima, en el caso del gas debía hacerse exclusivamente por ductos transfronterizos dadas las características de su comercialización señaladas anteriormente.

El mercado regional de gas se materializó a través del emplazamiento de una decena de gasoductos de exportación entre 1997 y 2002. Cuentan con una capacidad total de transporte de 42 millones de metros cúbicos por día $\left(\mathrm{MMm}^{3} / \mathrm{d}\right)$, equivalente a un tercio de la producción local de 2001: siete dirigidos a Chile, dos a Uruguay y uno a Brasil (ver cuadro 1). Tanto la construcción de los gasoductos como los contratos entre vendedores y compradores se realizó por parte de operadores mayormente privados. Los Estados se limitaron a garantizar las condiciones generales para el intercambio comercial. No se crearon organismos de seguimiento de los compromisos asumidos y tampoco mecanismos de anticipación de situaciones de riesgo de suministro (Bertero, 2007).

En 1995 Argentina y Chile firmaron el Protocolo de Integración Gasífera $^{11}$ por medio de sus respectivos presidentes, Carlos Menem y Eduardo Frei. El protocolo estableció la liberalización de la interconexión

11 El 2 de agosto de 1991, en el marco de la Asociación Latinoamericana de Integración (ALADI), Argentina y Chile firmaron el Acuerdo de Complementación Económica 16 (ACE 16). En el Protocolo Adicional 15, firmado en noviembre de 1995, se acordaron las Normas que Regulan la Interconexión Gasífera y el Suministro de Gas Natural entre la República de Chile y la República Argentina. 
gasífera y el suministro de gas natural entre Chile y Argentina, entregando la iniciativa a los actores privados (Gamboa \& Huneeus, 2007) ${ }^{12}$. Las partes se comprometían a no poner restricciones a que las empresas comercializaran gas natural con el país vecino — sin volumen límitepero en el artículo 2 se aclaraba que le correspondía a la Secretaría de Energía, en el caso argentino, y al Ministerio de Economía, Fomento y Reconstrucción, en el caso chileno, "considerar las solicitudes a fin de otorgar los respectivos permisos de exportación de gas natural, en la medida que no se comprometa el abastecimiento interno al momento del otorgamiento, si la legislación de las Partes así lo requiere”. Entre 1997 y 1999 se pusieron en operación siete gasoductos con una capacidad total de 32,8 $\mathrm{MMm}^{3} / \mathrm{d}$ y los principales exportadores eran, entre otros, Repsol YPF, Pan American Energy, Total, Wintershall y ENAP Sipetrol (filial de la petrolera estatal chilena). El gas argentino resultó un insumo clave y barato para la producción de metanol, la generación eléctrica y el sector minero-industrial de Chile: el precio promedio en 1997 era de 1 dólar por millón de BTU (unidad térmica británica) y hasta 2006 no superó los 2 dólares, según datos de Navajas (2008, p. 48).

En abril de 1996 Argentina y Brasil acordaron un Protocolo de Intenciones sobre Integración en Materia Energética ${ }^{13}$, que promueve la complementación de los sectores eléctrico y de gas. En materia gasífera, se ponían en consideración las reservas de gas natural en Argentina y las necesidades de Brasil, especialmente en el Estado de Río Grande du Sul. A su vez, las partes se comprometían a generar las condiciones normativas que liberalizarían la comercialización entre empresas de los dos países, pero se mantenía como marco normativo aplicable la respectiva legislación de cada país. En agosto de 2000, se inauguró el gasoducto Aldea Brasilera-Uruguayana con capacidad

\footnotetext{
12 Respecto al protocolo, Oscar Secco, presidente del IAPG, afirmó: "Los Estados no definen $[\ldots]$ quiénes pueden construir gasoductos, instalar usinas generadoras o tender líneas eléctricas. Sólo se limitan a asegurar que exista competencia y que se respeten las normas de seguridad y de sustentabilidad ambiental" (Petrotecnia, diciembre de 1999, p. 3).

13 En diciembre de 1990 Argentina y Brasil firmaron el Acuerdo de Complementación Económica 14 (ACE 14) en el marco de la ALADI, con el objetivo de crear las condiciones necesarias para el establecimiento de un mercado común, aunque no se especificaron normas sobre integración gasífera.
} 
de 2,8 $\mathrm{MMm}^{3} / \mathrm{d}$. El gas lo aportaba Repsol YPF y, en principio, abasteció a la central eléctrica de Uruguayana aunque estaba prevista su extensión hasta Porto Alegre.

Respecto a la exportación al mercado uruguayo, en 1991 ambos países habían firmado el Acuerdo de abastecimiento de gas natural argentino a la República Oriental del Uruguay, que recién en 1996, mediante el Acuerdo Complementario, amplió y profundizó las condiciones para la libre comercialización del gas argentino. La interconexión se realizó a través de dos gasoductos con capacidad de transporte de $7 \mathrm{MMm}^{3}$ /d: el Litoral, operado por Petrouruguay S.A. —empresa controlada por la petrolera estatal uruguaya ANCAP- y Cruz del Sur, operado por un consorcio privado con participación de ANCAP, aunque fue inaugurado en forma posterior al periodo de estudio. Cabe notar que, de los diez gasoductos transfronterizos construidos, solamente el gasoducto Petrouruguay es totalmente operado por una empresa estatal. El resto pertenecen a consorcios privados, en dos de ellos participan las estatales ENAP y ANCAP.

\section{Cuadro 1. Ductos transfronterizos de transporte de hidrocarburos con origen en Argentina}

\begin{tabular}{|c|c|c|c|c|c|}
\hline Ducto & $\begin{array}{l}\text { Cabecera } \\
\text {-terminal }\end{array}$ & $\begin{array}{l}\text { Cabecera } \\
\text {-terminal }\end{array}$ & $\begin{array}{c}\text { Destino } \\
\text { principal }\end{array}$ & $\begin{array}{c}\text { Capacidad } \\
\text { de } \\
\text { Capacidad }\end{array}$ & $\begin{array}{c}\text { Capacidad } \\
\text { de } \\
\text { operación }\end{array}$ \\
\hline $\begin{array}{l}\text { Oleoducto } \\
\text { Trasandino }\end{array}$ & $\begin{array}{l}\text { Puesto } \\
\text { Hernández - } \\
\text { Concepción }\end{array}$ & $\begin{array}{l}\text { YPF, Unocal } \\
\text { Corp. Y } \\
\text { Enap }\end{array}$ & $\begin{array}{l}\text { Enap } \\
\text { (refinación) }\end{array}$ & $\begin{array}{c}115 \\
(\mathrm{MB} / \mathrm{d})\end{array}$ & 1994 \\
\hline $\begin{array}{c}\text { Gasoducto } \\
\text { Methanex PA }\end{array}$ & $\begin{array}{c}\text { San } \\
\text { Sebastián - } \\
\text { Bandurrias }\end{array}$ & Bridas & $\begin{array}{l}\text { Methanex } \\
\text { (producción de } \\
\text { metanol) }\end{array}$ & $\begin{array}{c}2(\mathrm{MMm} 3 / \\
\text { día })\end{array}$ & 1997 \\
\hline $\begin{array}{c}\text { Gasoducto } \\
\text { Methanex YPF }\end{array}$ & $\begin{array}{l}\text { El Cóndor - } \\
\text { Posesión }\end{array}$ & Repsol YPF & $\begin{array}{c}\text { Methanex } \\
\text { (producción de } \\
\text { metanol) }\end{array}$ & $\begin{array}{c}2 \text { (Mía) } \\
\text { MMm3/ }\end{array}$ & 1999 \\
\hline $\begin{array}{c}\text { Gasoducto } \\
\text { Methanex SIP }\end{array}$ & $\begin{array}{c}\text { Cabo } \\
\text { Vírgenes - } \\
\text { Dungeness }\end{array}$ & Sipetrol & $\begin{array}{c}\text { Methanex } \\
\text { (producción de } \\
\text { metanol) }\end{array}$ & $\begin{array}{c}1,3 \\
\underset{\text { día })}{\left(\mathrm{MMm}_{3}\right.}\end{array}$ & 1999 \\
\hline $\begin{array}{l}\text { Gasoducto } \\
\text { Atacama }\end{array}$ & $\begin{array}{l}\text { Cnel. } \\
\text { Cornejo - } \\
\text { Mejillones }\end{array}$ & $\begin{array}{l}\text { CMS Energy, } \\
\text { Endesa, } \\
\text { Pluspetrol y } \\
\text { Repsol } \\
\text { YPF }\end{array}$ & $\begin{array}{c}\text { Sector industrial } \\
\text { y minero y } \\
\text { generación } \\
\text { eléctrica }\end{array}$ & 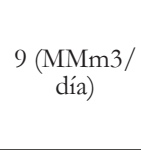 & 1999 \\
\hline
\end{tabular}




\begin{tabular}{|c|c|c|c|c|c|}
\hline Ducto & $\begin{array}{l}\text { Cabecera } \\
\text {-terminal }\end{array}$ & $\begin{array}{l}\text { Cabecera } \\
\text {-terminal }\end{array}$ & $\begin{array}{l}\text { Destino } \\
\text { principal }\end{array}$ & $\begin{array}{c}\text { Capacidad } \\
\text { de } \\
\text { Capacidad }\end{array}$ & $\begin{array}{c}\text { Capacidad } \\
\text { de } \\
\text { operación }\end{array}$ \\
\hline $\begin{array}{l}\text { Gasoducto } \\
\text { Pacífico }\end{array}$ & $\begin{array}{c}\text { Loma La } \\
\text { Lata - } \\
\text { Talcahuano }\end{array}$ & $\begin{array}{c}\text { TransCanada, } \\
\text { Repsol } \\
\text { YPF, El Paso, } \\
\text { Gasco y } \\
\text { Enap }\end{array}$ & $\begin{array}{l}\text { Sector industrial, } \\
\text { comercial y } \\
\text { residencial de } \\
\text { Concepción }\end{array}$ & $\begin{array}{c}\text { 3,5 } \\
\text { (MMm3/ } \\
\text { día) }\end{array}$ & 1999 \\
\hline $\begin{array}{c}\text { Gasoducto Gas } \\
\text { Andes }\end{array}$ & $\begin{array}{l}\text { La Mora - } \\
\text { San } \\
\text { Bernardo }\end{array}$ & $\begin{array}{c}\text { TransCanada, } \\
\text { CGC, } \\
\text { Gener y } \\
\text { Santiago } \\
\text { Metrogas }\end{array}$ & $\begin{array}{c}\text { Gener } \\
\text { (generación } \\
\text { eléctrica) y } \\
\text { Santiago } \\
\text { Metrogas } \\
\text { (distribuidora } \\
\text { de gas) }\end{array}$ & $\begin{array}{c}10 \\
\underset{\text { día })}{\left(\mathrm{Mm}_{3} 3 /\right.}\end{array}$ & 1997 \\
\hline $\begin{array}{l}\text { Gasoducto } \\
\text { Norandino }\end{array}$ & $\begin{array}{l}\text { Pichanal } \\
\text { - Tocopilla }\end{array}$ & $\begin{array}{l}\text { Tractebel y } \\
\text { US-based } \\
\text { Southern } \\
\text { Electric }\end{array}$ & $\begin{array}{l}\text { Sector industrial } \\
\text { y minero y } \\
\text { generación } \\
\text { eléctrica }\end{array}$ & $\begin{array}{c}5\left(\mathrm{MMm}^{\mathrm{M}} 3 / \mathrm{a}\right) \\
\text { dí }\end{array}$ & 1999 \\
\hline $\begin{array}{l}\text { Gasoducto } \\
\text { Petrouruguay }\end{array}$ & $\begin{array}{l}\text { Colón } \\
\text { - Paysandú }\end{array}$ & $\begin{array}{c}\text { Petrouruguay } \\
\text { (ANCAP) }\end{array}$ & Sector industrial & $\begin{array}{c}1 \text { (MMm3/ } \\
\text { día) }\end{array}$ & 1998 \\
\hline $\begin{array}{l}\text { Gasoducto } \\
\text { Cruz } \\
\text { del Sur }\end{array}$ & $\begin{array}{l}\text { Ensenada - } \\
\text { Montevideo }\end{array}$ & $\begin{array}{c}\text { British Gas, } \\
\text { PAE, } \\
\text { ANCAP y } \\
\text { Wintershall }\end{array}$ & $\begin{array}{l}\text { Sector industrial } \\
\text { y residencial }\end{array}$ & $\begin{array}{c}6(\mathrm{MMm} 3 / \\
\text { día) }\end{array}$ & 2002 \\
\hline $\begin{array}{l}\text { Gasoducto } \\
\text { Uruguayana } \\
\text { (TGM) }\end{array}$ & $\begin{array}{c}\text { Aldea } \\
\text { Brasileira - } \\
\text { Uruguayana }\end{array}$ & $\begin{array}{c}\text { TGN } \\
\text { (Techint, } \\
\text { CGC, } \\
\text { TransCanada, } \\
\text { Petronas y } \\
\text { CMS) }\end{array}$ & $\begin{array}{l}\text { Generación } \\
\text { eléctrica }\end{array}$ & $\begin{array}{c}2,8 \\
\underset{\text { día })}{\left(\mathrm{MMm}_{3} 3 /\right.}\end{array}$ & 2000 \\
\hline
\end{tabular}

Fuente: elaboración propia en base a datos de la Fundación Bariloche (2007, p. 198) y a información recabada en las webs institucionales de las empresas.

A nivel multilateral, los Estados parte del Mercosur suscribieron en 1999 un memorándum relativo a la integración gasífera, por el cual Argentina, Brasil, Uruguay y Paraguay se comprometían a desarrollar un mercado regional de gas natural en el cual operen tanto empresas públicas como privadas, bajo las reglas del librecomercio y la competencia.

Si esta estrategia de integración respondía al regionalismo abierto, su énfasis estuvo puesto más en la integración negativa que en la integración positiva; es decir, más centrada en la liberalización comercial intragrupo que en la elaboración de políticas comunes y en la creación de instituciones acordes (Sanahuja, 2008, p. 14). Los objetivos del memorándum del Mercosur incluían asegurar los mecanismos legales y la infraestructura física necesaria para comercializar libremente 
el gas, pero dejaban de lado menciones a políticas de desarrollo e industrialización del recurso entre los Estados miembros.

Cabe destacar que los asuntos energéticos en el Mercosur se tratan en el Subgrupo de Trabajo 9 (SGT 9), pero las normativas legales de integración energética no han registrado avances en cuanto a la incorporación de dispositivos para la solución de controversias ni para normar situaciones de crisis (Ruiz-Caro, 2010, p. 55), y se evidencia la inexistencia de un cuadro institucional multilateral para reglamentar y coordinar los procesos de integración en el sector energético (Ceia \& Gonçalves Ribeiro, 2016, p. 57).

Un informe de la Fundación Bariloche (2007) concluye que la integración ha sido preponderantemente física, con una alta vulnerabilidad desde el punto de vista de la integración gubernamental y regulatoria (p. 202). Más enfáticamente, Raúl Bertero (2007) asegura que el desarrollo de interconexiones energéticas sin una concepción estratégica — tal como sucedió con los gasoductos de exportación de gas de Argentina a Chile_ no puede entenderse como integración energética (p. 55). En cambio, desde el punto de vista de la presente investigación, la ausencia de una visión estratégica es inherente a la integración energética según los preceptos neoliberales: la interconexión física y comercial se realiza exclusivamente en función de la acumulación de capital.

\section{Excedentes de exportación}

Con el fin de visualizar el cambio producido a fines de la década del 80, se elaboró una serie temporal con datos de extracción, importación, exportación y consumo aparente ${ }^{14}$ tanto de petróleo como de gas entre 1975 y 2001, según datos oficiales del MINEM. Se seleccionó como inicio 1975 dado que fue el año en el cual se abrió la importación de gas natural desde Bolivia y como cierre 2001 por ser

\footnotetext{
14 Por consumo aparente entendemos la suma de la extracción y de la importación, menos la exportación. De ese modo se obtiene una aproximación a la demanda interna, aunque no se tienen en cuenta otros datos no menos importantes como el almacenaje o acumulación de existencias, en el caso del crudo, y las pérdidas, en el caso del gas natural.
} 
el año de la mayor crisis de la historia argentina, a partir de la cual se modificarían algunos principios de la reforma neoliberal del sector hidrocarburífero. Esta serie se dividió en dos: la etapa de estudio propiamente dicha, 1989-2001, y la etapa precedente, 1975-1988, con el fin de compararlas.

En el periodo 1975-1988, el consumo aparente de crudo se mantuvo estable con $440 \mathrm{mil} \mathrm{b/d}$, con un pico en 1980 de 534 mil. La extracción registró un aumento de 13,4\% al pasar de 396 mil b/d a 449 mil. Desde 1976, la importación se redujo significativamente, pasó de 60 mil b/d hasta extinguirse a partir de 1983. En 1985 se reanudaron las exportaciones de crudo — que no se registraban desde 1975con casi $9 \mathrm{mil} \mathrm{b/d}$, aunque apenas representaban el 2\% del total del crudo producido ese año.

En el periodo siguiente, entre 1989 y 2001, el consumo aparente se incrementó 23,8\% entre ambos extremos: de 448 mil pasó a 555 mil b/d; mientras que la extracción aumentó 67\%: pasó de 460 mil a $768 \mathrm{mil} \mathrm{b} / \mathrm{d}$. Producto de esa diferencia, la exportación creció nada menos que 19, 34\%, de 12 mil a 241 mil b/d entre esos años. El año pico de exportación de crudo fue 1997 con $335 \mathrm{mil} \mathrm{b/d}$, por lo que el mercado externo llegó a representar el 40\% del crudo extraído. Posteriormente, esa relación se reduciría gradualmente (gráfico 1).

Si la tasa anual acumulativa de extracción en el periodo precedente era de apenas $1 \%$ y prácticamente invariable en el caso del consumo, la tasa de extracción en el periodo de estudio subió hasta 4,4\% y la de consumo hasta 1,8\%. Una diferencia de 2,6 puntos porcentuales. Esa diferencia entre las tasas de extracción y consumo se estira hasta casi 5 puntos porcentuales cuando se realiza un recorte del intervalo 1989-1998: $7 \%$ frente a 2,1\%, respectivamente ${ }^{15}$.

\footnotetext{
15 En el marco de la reforma neoliberal analizada, los operadores privados privilegiaron la inversión de bajo riesgo. Esto se verifica en la acentuada caída de la relación entre pozos de desarrollo o de producción y de exploración, aquellos que se hacen para encontrar nuevas reservas. Según datos del Instituto Argentino del Petróleo y Gas, en 1989 se realizaron 711 pozos de desarrollo y 98 pozos de exploración (1 de exploración por cada 7 de explotación), mientras que en 2001 se hicieron 1291 y 33, respectivamente (1 de exploración por cada 39 de explotación).
} 


\section{Gráfico 1. Extracción, consumo aparente e importación de petróleo crudo entre 1975-2001 (en barriles por día)}

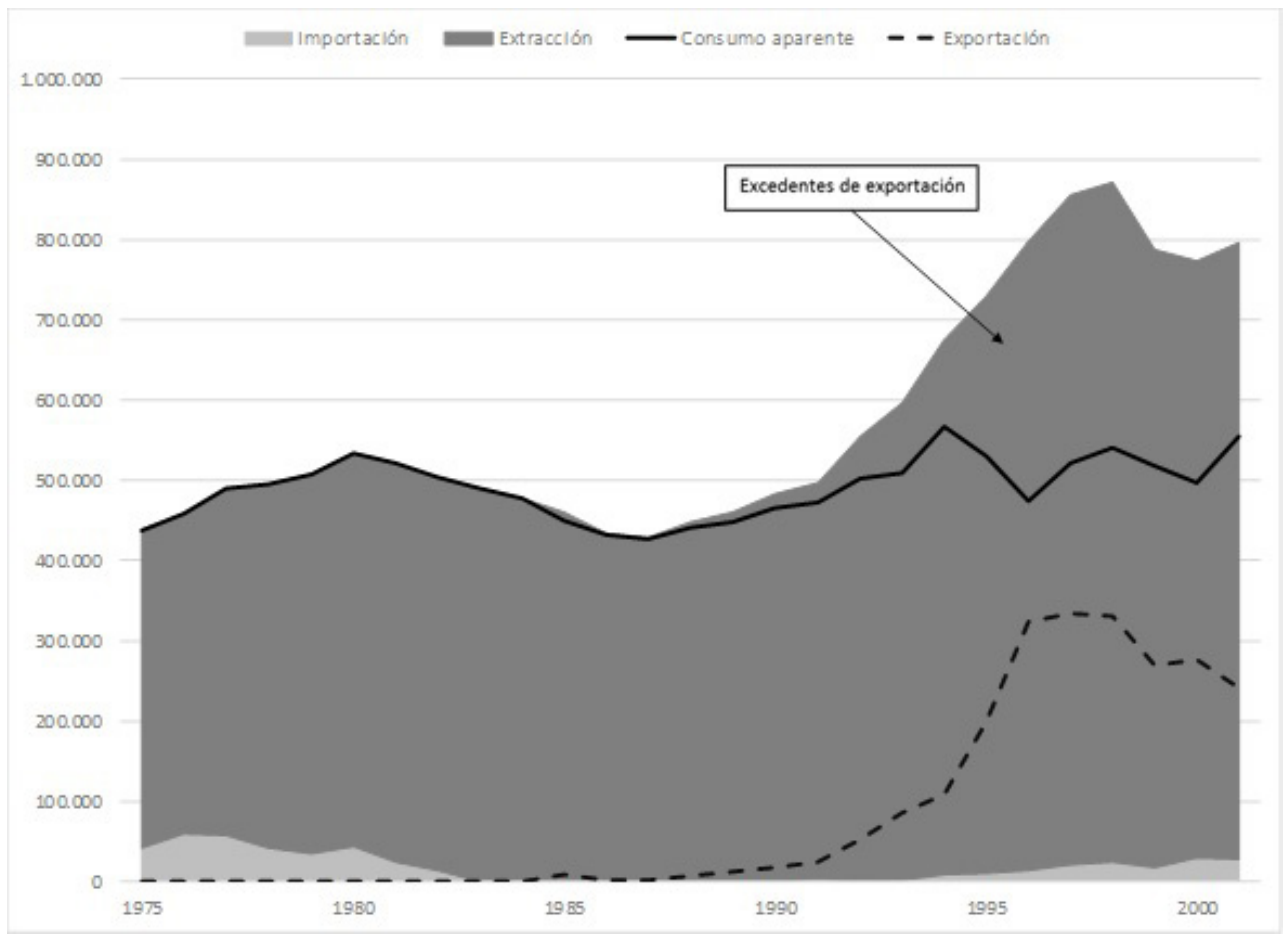

Fuente: elaboración propia en base a datos del MINEM.

En 1998, se observa un freno al ritmo exportador (con una caída interanual de 1,4\%) y en el bienio 1999-2000 un retroceso tanto de la extracción como del consumo. Esto se debe a que el esquema favorable para la apropiación mercantil por parte de las petroleras privadas se vio afectado por la caída del precio internacional del barril de crudo a fines de la década del noventa. Bajo su condición

A su vez, la inversión privada se concentró en ciertas áreas centrales — las de mayor producción y mayor rentabilidad—, que habían sido exploradas y desarrolladas por YPF estatal. Así lo demuestra Kozulj (2002) en su informe para CEPAL, a partir del análisis de la evolución de la tasa de extracción área por área (pp. 42-43). También la generalización de la técnica de recuperación secundaria — fundamentalmente a través de la inyección de agua para aumentar la presión del reservorio- permitió incrementar la tasa de extracción (Gadano, 1998; Barrera, 2013). 
de commodity, la cotización internacional regula en buena medida la dinámica de la apropiación privada del petróleo ${ }^{16}$.

Aproximadamente el 70\% de las ventas externas de crudo tuvieron como destino países del Cono Sur. El año de mayor participación de esta región en las exportaciones de crudo fue el 2000, que explica el 76,6\% del total, con $212 \mathrm{mil} \mathrm{b/d}$. A partir de datos del MINEM ${ }^{17}$, se constata que en un comienzo las exportaciones se dirigieron principalmente hacia Brasil y en 1996 ese mercado concentró el 40\% de las ventas totales con $132 \mathrm{mil}$ b/d. En una segunda instancia, las exportaciones se concentraron mayormente en Chile hasta alcanzar un pico de casi $150 \mathrm{mil} \mathrm{b/d}$ en 2001. En gran medida, ese resultado fue facilitado por el emplazamiento del Oleoducto Trasandino. De menor magnitud, las exportaciones hacia Uruguay y Paraguay tuvieron picos en 1995 y 1996, con 11 mil y 3 mil b/d, respectivamente.

En cuanto al gas natural, en la etapa precedente se verifica un salto notable tanto del consumo aparente - un incremento de $110 \%$, pasando de 32 millones de $\mathrm{m}^{3}$ por día en promedio $\left(\mathrm{MMm}^{3} / \mathrm{d}\right)$ a 68 millones - como de la extracción — crecimiento de $120 \%$, pasando de 28 a $62 \mathrm{MMm}^{3} / \mathrm{d}$ - El salto estuvo vinculado a la puesta en marcha del yacimiento Loma la Lata en la Cuenca Neuquina, el más grande del país, y a la expansión de la red de gasoductos interna que posibilitaron la gradual gasificación de la matriz energética argentina. Sumado a ello, el gas entregado por Bolivia fue inicialmente de 4,2 $\mathrm{MMm}^{3}$ /d y aumentó 43\% hasta alcanzar $6 \mathrm{MMm}^{3}$ /d en 1988.

En el periodo 1989-2001 se observa una continuidad del ritmo de extracción: entre ambos extremos trepó $98,4 \%$, a una tasa anual acumulativa de 5,9\% (apenas por debajo de la tasa de 6,3\% del periodo anterior),

\footnotetext{
16 El precio del barril de crudo West Texas Intermediate (WTI) cayó 55\% entre diciembre de 1996 y diciembre de 1998: pasó de 25,2 a 11,3 dólares, según datos de EIA. Cabe aclarar que no fue el único factor que pudo explicar la caída de la actividad: también se deben tener en cuenta el comienzo de la recesión de la economía local y la reducción de la demanda de crudo por parte de Brasil.

17 Las tablas dinámicas del MINEM cuentan con datos de exportación de crudo discriminado por país de destino solamente a partir de 1994.
} 
pasando de 66 a $131 \mathrm{MMm}^{3} / \mathrm{d}$. En cambio, el consumo creció a un ritmo marcadamente inferior: en total se expandió 58\% (de 72 a 114 $\mathrm{MMm}^{3}$ /d) pero a una tasa anual acumulativa de 3,9\% contra una tasa de $5,9 \%$ del periodo anterior. La diferencia entre las tasas de extracción $\mathrm{y}$ de consumo en el periodo precedente fue de apenas 0,4 puntos porcentuales, aunque Argentina mantenía su condición de país importador, y en el periodo de estudio se amplió a 2 puntos.

El contrato de importación con Bolivia culminó en 1999, con lo cual la producción local debió suplir a partir de entonces el gas importado. Aun así, se generaron sobrados excedentes respecto al consumo interno ${ }^{18}$ con el fin de destinarlos a los mercados limítrofes. Las exportaciones comenzaron en 1997 con 1,8 $\mathrm{MMm}^{3} / \mathrm{d}$ y se incrementaron considerablemente en la medida en que se puso en marcha cada gasoducto transfronterizo hasta casi $17 \mathrm{MMm}^{3} / \mathrm{d}$ en 2001 (ver gráfico 2). Esto fue posible debido a que la tasa anual acumulativa de extracción del intervalo 1997-2001 fue de 6,7\%, mientras que la tasa de consumo fue de solo $2,4 \%$, lo que generó una diferencia de 4,3 puntos porcentuales entre ambas tasas.

El principal destino del gas argentino fue Chile, concentrando al menos el $87 \%$ de las exportaciones en forma anual. Según datos del ENARGAS, la venta de gas al mercado chileno pasó de 1,8 MMm3/d en 1997 a 14 MMm3/d en 2001.

El mercado brasileño recibió gas argentino a partir del año 2000 y en 2001 alcanzó un volumen de $2 \mathrm{MMm}^{3}$ /d, que representó el 12\% de las exportaciones. Por último, el mercado uruguayo se abrió como destino en 1998 pero hasta el cierre del periodo de estudio no recibía más

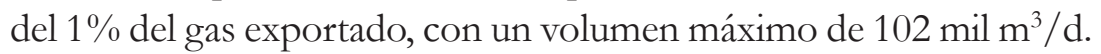

\footnotetext{
18 Optamos por el concepto consumo interno en lugar de demanda interna porque el freno a la expansión de la red de gasoductos nacional a partir de 1989 imposibilitó que algunas regiones del país pudieran acceder al gas natural. El concepto excedente se vuelve relativo respecto a una demanda potencial insatisfecha, pero lo utilizamos en función de la estrategia exportadora trazada en aquel entonces.
} 
Gráfico 2. Extracción, consumo aparente, importación y exportación de gas natural entre 1975-2001 (en $\mathrm{m}^{3}$ por día)

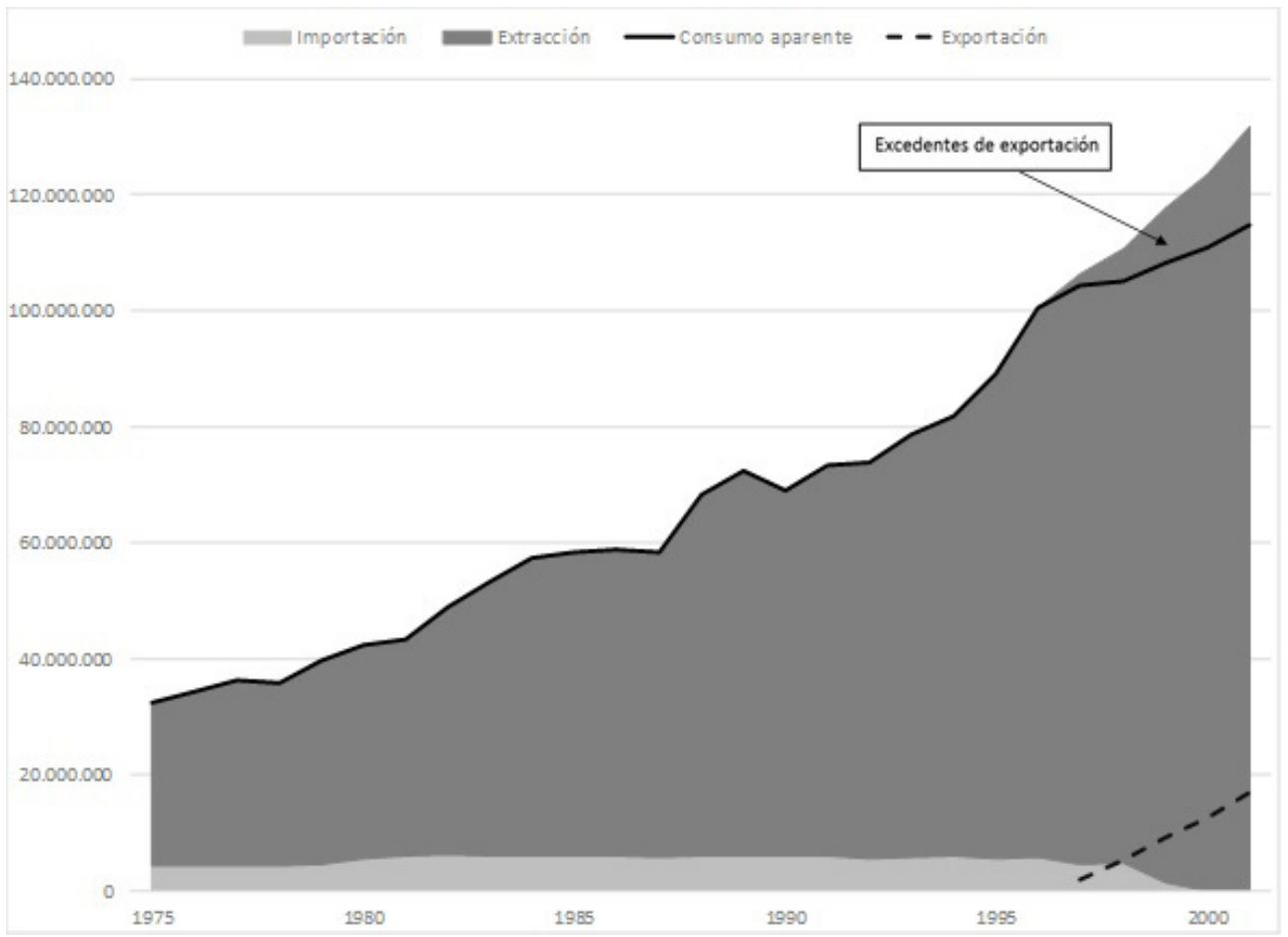

Fuente: elaboración propia en base a datos del MINEM.

A partir de la reforma del sector hidrocarburífero argentino, Chile se convirtió en el principal importador tanto de gas natural como de petróleo (en una segunda etapa), debido a la escasa disponibilidad de hidrocarburos en su territorio comparado con Brasil y al mayor tamaño de su mercado con relación al uruguayo, dentro de la subregión. La fuerte dependencia que adoptó el sistema energético chileno respecto a la importación de hidrocarburos desde Argentina, sobre todo del gas natural, generaría una fuerte crisis bilateral en la década siguiente, cuando el gobierno argentino decidiera restringir las exportaciones para resguardar el abastecimiento interno. Este tema será profundizado en un próximo artículo. 


\section{Conclusiones}

Repasando el material documental registrado, sistematizado y analizado, se obtuvieron los siguientes resultados: los acuerdos intergubernamentales recolectados fueron firmados en forma posterior a la implementación de la reforma, fundamentalmente en el segundo quinquenio de la década del noventa. Solamente el acuerdo suscripto con el gobierno uruguayo se firmó a comienzos de la reforma, incluso antes de la aprobación de la ley de privatización de YPF, que requirió un acuerdo complementario para profundizar en los criterios desreguladores del intercambio comercial de gas natural. En todos los acuerdos, se comprueba que el Estado en su forma neoliberal se limita a ser garante del libre desenvolvimiento del mercado subregional y a avalar el emplazamiento de ductos transfronterizos de exportación, los cuales fueron concebidos por consorcios privados formados por empresas nacionales y extranjeras.

Asimismo, se profundizó la perspectiva de los actores privados mediante el análisis de contenido cualitativo del medio gráfico de comunicación del organismo que agrupa a los principales operadores petroleros y gasíferos del país. De esta manera, se detectó una construcción discursiva en torno a la necesidad de otorgar a Argentina el rol de exportador/ proveedor de hidrocarburos en el Cono Sur y a su vez la integración subregional como requisito de la inversión no solo en extracción, sino también en exploración. Desde este punto de vista, el tamaño del mercado interno era insuficiente para el ritmo de acumulación del capital petrolero y, por lo tanto, sus representantes operaron material y simbólicamente para crear el mercado subregional.

Por último, los datos obtenidos del mercado primario de hidrocarburos permitieron verificar que, a partir de 1989, año en el que comenzó la reforma neoliberal, hubo un fuerte viraje del objetivo del autoabastecimiento hacia la generación de saldos exportables. En otras palabras, se evidenció la transformación de Argentina en un país exportador al cabo de muy pocos años, a diferencia del periodo anterior en el cual exportaba ocasionalmente sobrantes de crudo y era deficitario en materia de gas natural. Se observa una diferencia más que amplia entre las tasas de extracción y de consumo, que se 
exacerbó en el intervalo 1989-1998 en el caso del petróleo y en el subperiodo 1997-2001, en el caso del gas. La producción de excedentes habilitó el proceso de integración de Argentina como proveedor de hidrocarburos del Cono Sur.

Dicho esto, se puede concluir que sin la reforma sectorial, la estrategia de integración energética como país exportador hubiese sido impensable. Los hidrocarburos convertidos en mercancías exportables encontraron en el mercado regional la mejor salida. Los países limítrofes son en gran parte importadores de los mismos y además el gas solo podía exportarse vía terrestre dadas las condiciones tecnológicas de la época. Por dichos factores, la reforma neoliberal del sector fue condición necesaria, aunque no suficiente, para la integración regional como país exportador.

De ese modo, se verifica la hipótesis inicial: primó una integración "de hecho" porque el motor de esta fue el interés privado por monetizar las reservas de hidrocarburos lo más rápido posible. La estrategia de las empresas privadas, incluida YPF S.A., fue facilitada por la desregulación y comoditización instrumentada por el Estado neoliberal.

Complementariamente sobrevino una integración impulsada por políticas en la cual el Gobierno argentino suscribió los acuerdos necesarios con los países limítrofes para garantizar el intercambio comercial de gas por gasoductos. La armonía de intereses entre Estado neoliberal y capital petrolero facilitó la inserción regional del país como proveedor de hidrocarburos en función de un régimen de acumulación que prescindía de los mismos como recursos estratégicos para el abastecimiento interno.

Por todo lo expuesto, se propone la categoría integración neoliberal para denominar a los procesos regionales en los cuales predomina la integración "de hecho" dirigida por el sector privado por sobre la integración impulsada por políticas, es decir, orientada estratégicamente por los Estados. 
Finalmente, las conclusiones aquí vertidas son relevantes para las políticas de integración regional en dos aspectos: institucional y sectorial. Respecto al primer aspecto, existe sobrada evidencia sobre la debilidad institucional y la ausencia de una concepción estratégica para la formalización de los acuerdos subregionales en materia de hidrocarburos, que fue señalada por otros autores. En este artículo, se agrega que esta debilidad es producto del andamiaje normativo construido a partir de la reforma neoliberal del sector, que dejó al Estado desprovisto del manejo de su empresa petrolera y de herramientas regulatorias a favor de la iniciativa del capital petrolero. En cuanto al aspecto sectorial, el artículo pretende llamar la atención sobre los límites de todo proceso de integración regional basado en la comercialización de bienes naturales no renovables que se precie sustentable. La disponibilidad natural de petróleo y gas en el subsuelo argentino es generosa con relación al tamaño de su economía, pero nada hacía suponer que pudiera convertirse en proveedor de toda la subregión en el largo plazo.

Como consecuencia de la sobreexplotación de las áreas petroleras y gasíferas y de la subexploración de nuevas áreas, se produjo una caída del horizonte de reservas que resultó incompatible para cubrir el crecimiento de la demanda interna y los compromisos de exportación en la década siguiente. La tensión diplomática con los países limítrofes, fundamentalmente con Chile, que originó la implementación de restricciones a la estrategia exportadora del sector privado, demuestra cuán dañino puede ser un proceso de integración que delegue su conducción a las fuerzas del mercado y que no repare en la finitud de los recursos comercializados.

\section{Anexo l: Acuerdos y protocolos internacionales en materia de hidrocarburos}

Acuerdo de Complementación Económica 16 (ACE 16) entre la República de Chile y la República Argentina. 2 de agosto de 1991. 
Acuerdo de Complementación Económica 14 (ACE 14) entre la República Federativa de Brasil y la República Argentina. Diciembre de 1990.

Acuerdo de Abastecimiento de Gas Natural Argentino a la República Oriental del Uruguay. 8 de julio de 1991.

Acuerdo Complementario al Acuerdo de Abastecimiento de Gas Argentino a la República Oriental del Uruguay. 20 de septiembre de 1996.

Memorándum de Entendimiento Relativo a los Intercambios Gasíferos e Integración Gasífera entre los Estados Partes del Mercorsur.7 de diciembre de 1999.

Protocolo Adicional 15 (Protocolo Sustitutivo del Protocolo 2 del Acuerdo de Complementación Económica 16 entre la Republica de Chile y la Republica Argentina). Normas que Regulan la Interconexión Gasífera y el Suministro de Gas Natural entre la República de Chile y la República Argentina. 27 de noviembre de 1995.

Protocolo de Intenciones entre la República Argentina y la República Federativa del Brasil sobre Integración en Materia Energética. 9 de abril de 1996.

\section{Referencias}

Andréu Abela, J. (2001). Las técnicas de análisis de contenido: una revisión actualizada. Sevilla: CENTRA.

Arriaga Rodríguez, J. C. (2002). La posición de México frente al Proyecto de Integración Energética Hemisférica del ALCA. Aldea Mundo, 6(12), 75-84.

Azpiazu, D., \& Basualdo, E. (2004). Lasprivatizaciones en la Argentina. Génesis, desarrollo y principales impactos estructurales. Buenos Aires: FLACSO.

Azpiazu, D., \& Schorr, M. (2010). Hecho en Argentina. Industria y economia, 1976-2007. Buenos Aires: Siglo XXI Editores. 
Barrera, M. (2013). La “desregulación” del mercado de hidrocarburos y la privatización de YPF: Orígenes y desenvolvimiento de la crisis energética en Argentina. En F. Basualdo, M. Barrera \& E. Basualdo (Eds.), Las producciones primarias en la Argentina reciente: Minería, petróleo y agro pampeano (pp. 97-198). Buenos Aires: Cara o Ceca.

Barrera, M., Sabbatella, I., \& Serrani, E. (2012). Historia de una privatización. Cómo y por qué se perdió YPF. Buenos Aires: Capital Intelectual.

Basualdo, E. (2006). La reestructuración de la economía argentina durante las últimas décadas de la sustitución de importaciones a la valorización financiera. En E. Basualdo \& E. Arceo (Orgs.), Neoliberalismo y sectores dominantes. Tendencias globales y experiencias nacionales (pp. 123-177). Buenos Aires: CLACSO.

Basualdo, E., \& Arceo, E. (2006). Documento inicial. Los cambios de los sectores dominantes en América Latina bajo el neoliberalismo. La problemática propuesta. En E. Basualdo \& E. Arceo (Orgs.). Neoliberalismo y sectores dominantes. Tendencias globales y experiencias nacionales (pp. 15-26). Buenos Aires: ClACsO.

Basualdo, E., \& Barrera, M. (2015). Las privatizaciones periféricas en la dictadura cívico-militar. El caso de YPF en la producción de petróleo. Desarrollo Económico, 55(216), 279-304.

Bertero, R. (2007). Integración regional gasífera. Ciento ochenta años de proyecto de integración. Petrotecnia, (3), 54-60.

BID (2002). Mas allá de las fronteras: el nuevo regionalismo en América Latina. Buenos Aires: BID.

Boyer, R. (2016). La economía politica de los capitalismos. Buenos Aires: Universidad Nacional de Moreno.

Campodónico, H. (2004). Reformas e inversión en la industria de bidrocarburos de América Latina. Santiago de Chile: CEPAL.

CEPAL. (1994). El regionalismo abierto en América Latina y el Caribe. La integración económica al servicio de la transformación productiva con equidad. Santiago de Chile: CEPAL.

Ceia, E., \& Gonçalves Ribeiro, W. (2016). Modelos jurídicos e institucionales de integración energética: Unión Europea y Mercosur en perspectiva comparada. En N. J. de Castro \& R. Rosental (Orgs). Integración y seguridad eléctrica en América Latina (pp. 39-65). Rio de Janeiro: Oficina de Libros. 
Cerra, A., \& Yazbek, S. (2013). La Organización Latinoamericana de Energía (OLADE): los desafios de la integración regional en el sector de los hidrocarburos. Ponencia presentada en el V Congreso Anual de la Asociación de Economía para el Desarrollo de la Argentina, Buenos Aires.

EIA. (2017). WTI spotprice FOB. Recuperado de https://www.eia.gov/dnav/ pet $/$ hist $/$ LeafHandler.ashx? $=$ pet\&s $=$ rwtc $\& \mathrm{f}=\mathrm{m}$.

ENARGAS. (2017). Datos operativos de gas natural: gas exportado. Recuperado de http://www.enargas.gov.ar/secciones/transporte-y-distribucion/ datos-operativos-subsec. php?sec $=3 \&$ subsec $=4 \&$ subsecord $=03$

El petróleo y el gas en la Argentina del siglo XxI (abril 1994). Petrotecnia. Recuperado de http://biblioteca.iapg.org.ar/ArchivosAdjuntos/Petrotecnia/1994-1/Petroleo.pdf

El año de los gasoductos. (diciembre 1999). Petrotecria. Recuperado de http://biblioteca.iapg.org.ar/ArchivosAdjuntos/Petrotecnia/1999-6/ CartaPresidente.pdf

Favaro, O., \& Morinelli, M. (1991). Petróleo, estado y nación. Buenos Aires: CEAL. Fundación Bariloche. (2007). Asistencia técnica para la elaboración del "Plan Estratégico de Energía de la República Argentina". Informe final. Bariloche: Fundación Bariloche.

Gadano, N. (1998). Determinantes de la inversión en el sector petróleo y gas de la Argentina. Buenos Aires: CEPAL.

Gamboa, R., \& Huneeus, C. (2007). La interconexión gasífera Chile-Argentina: objetivos y actores. Estudios Internacionales, 157, 83-116.

Hallack, M. (2014). A integraçao da industria de gás natural na América do Sul: desafíos institucionais no desenvolvimento de infraestruturas de interconexao. En W. Desiderá Neto (Org). O Brasil e novas dimensoes da integraçao regional (pp. 353-414). Rio de Janeiro: IPEA.

Harvey, D. (2007). Breve historia del neoliberalismo. Madrid: Ediciones Akal. IAPG. (2017). Estadísticas interactivas. Recuperado de http://www.iapg.org. ar/estadisticasnew/

Kozulj, R., \& Bravo, V. (1993). La politica de desregulación petrolera argentina. Buenos Aires: Centro Editor de América Latina.

Kozulj, R. (2002). Balance de la privatización de la industria petrolera en Argentina y su impacto sobre las inversiones y la competencia en los mercados minoristas de combustibles. Santiago de Chile: CEPAL.

Kozulj, R. (2008). Situación y perspectivas del gas natural licuado en América del Sur. Santiago de Chile: CEPAL. 
Mansilla, D. (2007). Hidrocarburos y politica energética. De la importancia estratégica al valor económico: desregulación y privatización de los hidrocarburos en Argentina. Buenos Aires: Ediciones CCC.

Martínez Alier, J. (2004). El ecologismo de los pobres: conflictos ambientales y lenguajes de valoración. Barcelona: Icaria/Flacso.

Menem y Alwin pusieron en marcha la integración energética regional. (16 de febrero de 1994). El Cronista.

MINEM (2017). Producción de petróleo y gas. Recuperado de http:/ / www.energia. gob.ar/home/hidrocarburos.php

Navajas, F. (2008). La integración de la infraestructura y los contratos incompletos: el gas natural en el Cono Sur. Integración y comercio, 28, 27-53.

O’Connor, J. (2001). Causas naturales. Ensayos de marxismo ecológico. México: Siglo xxi Editores.

Palacio, G. (2006). Breve guía de introducción a la Ecología Política (Ecopol): orígenes, inspiradores, aportes y temas de actualidad. Revista Gestión y Ambiente, 3, 143-156.

¿Qué pasa con la producción de gas natural? (junio 1996). Petrotecnia.

¿Qué pasa con la producción de gas natural? (junio 1997). Petrotecnia.

Ramos Mejía, J. F. (2008). El régimen jurídico del abastecimiento interno de hidrocarburos. Petrotecnia, 49, 32-52.

Ruiz-Caro, A. (2010). Puntos de conflicto de la cooperación e integración energética en América Latina y el Caribe. Santiago de Chile: CEPAL.

Sabbatella, I. (2014). Neoliberalismo y naturaleza: la "comoditización" de los hidrocarburos en Argentina (1989-2001). Revista Iberoamericana de Economía Ecológica, (22), 101-116.

Sabbatella, I., \& Tagliavini, D. (2011). Marxismo ecológico: elementos fundamentales para la crítica de la economía-política-ecológica. Revista Herramienta, 47, 175-189.

Sanahuja, J. A. (2008). Del 'regionalismo abierto' al 'regionalismo post liberal'. Crisis y cambio en la integración en América Latina y el Caribe. En L. Martínez, L. Peña \& M. Vazquez (Eds). Anuario de la integración regional de América Latina y el Gran Caribe $2008-2009$ (pp. 11-54). Buenos Aires: CRIES.

Toledo, V. (2008). Metabolismos rurales: hacia una teoría económicoecológica de la apropiación de la naturaleza. Revista Iberoamericana de Economía Ecológica, (7), 1-26. 
212 / IgNACIO SABbATELLA

Valles, M. (1999). Técnicas cualitativas de investigación social. Reflexión metodológica y práctica profesional. Madrid: Síntesis.

Yabek, S. (2012). La integración petrolera en América Latina: el rol de ARPEL como comunidad epistémica. H-Industria, 6(10), 1-28. 